\title{
Development of Business Activities in the AgriculturalMachinery Market through Implementation of Cluster Initiatives
}

\author{
Alexander Natsubidse \\ Moscow Institute of State and Corporate Governance, Moscow, Russia \\ Tatiana Litvinova
}

Volgograd State Agrarian University, Volgograd, Russia

Tatiana Bezrukova

Voronezh State University of Forestry and Technologies named after G.F. Morozov, Voronezh, Russia

Boris Bezrukov

Voronezh State University of Forestry and Technologies named after G.F. Morozov, Voronezh, Russia

Doi:10.5901/mjss.2016.v7n1s1p401

\section{Abstract}

The authors substantiate the necessity for implementation of cluster initiatives for development of business activities in the agricultural machinery market. A starting point of the research is analysis of necessity for development of small business in developing countries, while in developed countries it plays a very important role in provision of economic growth. The authors suggest a hypothesis that development of business activities in the agricultural machinery market could be provided by implementation of cluster initiative. Methodological base for the research is systemic approach to analysis of business activities in the agricultural machinery market. Within this approach, the authors consider the main synergetic principles which are to be taken into account during the study of functioning of any system and build a matrix of infrastructural components in the agricultural machinery market. The authors determine the possibilities and perspectives of implementation of cluster initiatives in the agricultural machinery market. As a result, the authors come to a conclusion that the offered hypothesis is correct and implementation of cluster initiatives facilitates the development of business activities in the agricultural machinery market.

Keywords: entrepreneurship, small business, synergy, agricultural machinery market, cluster initiative, developed countries, developing countries.

\section{Introduction}

In the economies of most of developing countries, small business is not a stabilizing segment, like in countries with developed economy; the base of economy is comprised by subjects of large and medium business. Small business is paid certain attention which is still insufficient for making this sphere of social production important in the general results of functioning of national economy - both in economic and social aspect.

It should be noted that in most developed countries, small enterprises provide substantial stable revenues of the budgets of all levels, provide jobs for able-bodied population, and allow using unutilized resources in effective way. In this aspect, a problem of formation of possibilities for small business and their effective implementation in the economy of certain region, spheres, and state on the whole, as well as the problem of provision of effective combination of state and regional interests with private interests of entrepreneurs are very topical.

All economic subjects comprise a system of national economy, and, like many of its elements, are in certain interrelations and connections with each other; they interact with external environment and influence it on the principle of feedback. Small enterprises allow strengthening system's integrity and providing its sustainability - as they occupy the niches in which there are no larger economic subjects.

That's why, in order to achieve serious results in economic and social aspect, it is necessary to create conditions for development of economic subjects which refer to small business. This determines the topicality of the study of 
perspectives of entrepreneurship development. This research offers a hypothesis that development of business activities in the agricultural machinery market could be provided through implementation of cluster initiatives.

The purpose of the article is the study of possibilities and perspectives of development of business activities in the agricultural machinery market through realization of cluster initiatives. This purpose is achieved with the following tasks:

- study of business activities in the market of agricultural machinery from the point of view of systemic approach;

- building the matrix of infrastructural components in the agricultural machinery market;

- analysis of connection of main processes with infrastructural components and determination of the level of synergy of agricultural machinery market;

- determination of possibilities and perspectives of realization of cluster initiatives in agricultural machinery market.

The research is conducted with the help of the method of systemic approach, as this method allows viewing cluster as a totality of economic subjects interested in high final economic results, under optimal conditions of development and functioning and determining synergetic effect which emerges during conduct of activities by cluster subjects.

\section{Systemic Approach to the Analysis of Business Activities in the Agricultural Machinery Market}

Changes in the agricultural machinery market are caused both by external factors and by circumstances which are initiated by entrepreneurs within the market. Let's dwell more on the second position. A principle of changes within the market due to imbalance of main and supplementary processes is a basic one. They can stimulate negative or positive consequences. Positive ones are related to growth of synergetic effects.

Four main synergetic principles require attention; they should be taken into account during considering the functioning of any system (Carneiro et al., 2015):

1. Principle of systemic symmetrization-desymmetrization of Shubnikov-Curie.

2. Principle of structural and systemic diversity of W.R. Ashby.

3. Principle of multiplicity of description languages.

4. Principle of maximum of information.

At that, it should be noted that in the processes of evolution, adaptation, development, teaching, behavior, perception and discerning of images, and solving tasks, the system would choose the reactions which provide the maximum of average mutual information with set conditions of environment (stimuli). This should be understood as possibility for transforming the market depending on domination of one or another component of infrastructure.

Developed infrastructure supports main processes relating to manufacture of agricultural machinery which could be viewed as core of various negative influences of external environment. The more infrastructural components which are used within their limits of methods for achievement of goals, the higher the level of manufacturers' protection of unfavorable influence of external environment would be. Besides, infrastructure stipulates flexibility of demand and offer, thus evening the competitive level and positions of various market members.

Each element of infrastructure should be related to certain sphere of business activities in this market in order to provide the most effective functioning - though, sometimes entrepreneurs of infrastructure could stipulate the destruction of main market, which could be determined by fugacity of their goals. Essentially, infrastructure should help entrepreneurs working successfully in the following spheres (Mihajlović, 2014):

- marketing;

- financial;

- production.

Marketing activities at enterprise can be substantially optimized due to creation of systems which study the needs of agricultural machinery recipient, provide sales channels, create new value of agricultural machinery, and suppose creating feedback between manufacturers and consumers regarding quality and demand (perspectives of demand) of agricultural machinery (Reveiu \& Dârdală, 2015).

Success of financial activities is brought down to possibility of having necessary assets for development and it depends on many factors. However, impossibility of investments attraction always shows a very difficult state of enterprise. That's why infrastructure in this sphere should conduct the analysis of demand of investments and terms of their efficiency; provide assets for investments in various forms providing reduction of risks of incompleteness of investment projects. Production activity is characterized by such indicators as quality, cost, profitability, perspective, and implementation in future.

Generalizing the above mentioned, it should be noted that infrastructure should help to effectively use and find 
resources for implementation of entrepreneurial activities in one of the above mentioned spheres, stipulate the increase of the quality of entrepreneurial activities in these spheres, and facilitate the implementation of forms which are innovational and progressive in view of market development.

Enterprises which work in benchmarking in the agricultural machinery market are not many; thus, enterprises manufacturing agricultural machinery should compare main directions of business activities of their organization with similar indicators of other organizations. At that, the system of evaluation in this aspect in the market is actually isolated and limited informational deficits as to other enterprises. This approach does not allow increasing competitive advantage of enterprises in the internal and external markets.

There are also infrastructural components which are universal for all components of given matrix. For example, antimonopoly service which provides competitiveness of enterprise at marketing, financial, and production activities levels. State regulation, which is manifested in tax system, financial support and control of various forms of entrepreneurial activities of manufacturers of agricultural machinery and those who provide infrastructural provision of the market. Let us present the data, taking into account infrastructural elements which are present in the agricultural machinery market (Table 1).

Table 1. Matrix of infrastructural components in the agricultural machinery market

\begin{tabular}{|c|c|c|c|}
\hline & Marketing activities & Financial activities & Production activities \\
\hline $\begin{array}{l}\text { Resources supply. } \\
\text { Support for search and } \\
\text { optimization of } \\
\text { resources use }\end{array}$ & $\begin{array}{l}\text { Small network of } \\
\text { dealer firms }\end{array}$ & $\begin{array}{l}\text { Limitation: monopoly of } \\
\text { Rosselkhozbank and Sberbank of } \\
\text { Russia; stock market which is } \\
\text { constantly "pumped up" by the state }\end{array}$ & $\begin{array}{l}\text { Consulting companies providing services as to limited } \\
\text { issues, problematic leasing of equipment. }\end{array}$ \\
\hline $\begin{array}{l}\text { Support for increasing } \\
\text { the quality of business } \\
\text { activities }\end{array}$ & Absent & $\begin{array}{l}\text { Insurance funds do not have effective } \\
\text { goals. Project companies didn't } \\
\text { become popular }\end{array}$ & $\begin{array}{l}\text { Service divisions are not very popular and do not fulfill their } \\
\text { functions. Quality control is performed according to formal } \\
\text { order; there is no flexible approach to quality determination }\end{array}$ \\
\hline $\begin{array}{l}\text { Support for } \\
\text { innovational } \\
\text { development }\end{array}$ & $\begin{array}{l}\text { Weak rudiments of } \mathrm{E} \text { - } \\
\text { commerce. }\end{array}$ & Absent & $\begin{array}{l}\text { Connections with universities, technical schools, and } \\
\text { colleges which train staff are present, but their innovational } \\
\text { potential is low. Conference becomes more topical and } \\
\text { sufficient at modern level }\end{array}$ \\
\hline
\end{tabular}

Analyzing the connection between main processes and infrastructural components and taking into account the above mentioned, it is possible to see that the level of synergy, as the level of system sustainability to negative influences in the agricultural machinery market, is determined by the following (Geldes et al., 2015):

1. Sum of infrastructural components reflects the market's potential - both are at low level.

2. Diversity of infrastructure types does not allow providing the protection from external risks on necessary level.

3. Limitation of approaches within each infrastructural type does not add sustainability.

4. Informational transparency, defined as conditions for understanding the real state and building the most adequate relations between main and supplementary (infrastructural processes), is limited.

5. Shift of accents in infrastructure to production activities shows the perspectives of business activities' reflecting interests not of consumers and capital owners, which could result in insufficient understanding of market needs and reduction of business activities.

Factors of external environment influence certain components of infrastructure and main types of activities in this market, this determining the domination of some or other processes. At that, there is a need for the system based on infrastructure functionality. Its quality will increase with the growth of possibilities for conduct of entrepreneurial activities.

\section{Possibilities and Perspectives for Implementation of Cluster Initiatives in Agricultural Machinery Market}

At present, clustering hasn't yet found the proper use in economies of developing countries. At that, in order for economic subjects to achieve strategic flexibility of their activities, which allows reacting quickly and adequately to changes of external environment, it is possible to use the union of economic subjects aimed at achievement of various goals $-\mathrm{a}$ cluster.

Formation of possibilities within cluster and their effective use in the process of strategy implementation is performed on the basis of the use of advantages of combining prescriptive and descriptive approach. In this case, instability of external environment is, to a certain degree, compensated by sustainability of economic micro-climate of cluster and possibilities for using resources of other cluster members, and high level of motivation, generated by business activity of entrepreneurial subjects, allows providing stability of union's functioning. 
As is known, cluster is a network of interconnected subjects of production and commercial combination which includes manufacturers, suppliers, consumers, elements of industrial infrastructure, and research institutes which are effectively interconnected in the process of creation of value added. This formulation and the approach to cluster creation take into account the achievement of positive synergetic effects of regional agglomeration by means of proximity of manufacturer and consumer, cooperation, and specialization; network effects and quick diffusion by means of determining the most perspective directions and spheres of activity (Popkova \& Tinyakova, 2013a).

At that, there are no clear boundaries between types and sectors of activity, and the whole process of cooperation and unification of entrepreneurial subjects is viewed in interconnection, interdependence, and cooperation. A characteristic feature of this combination is possibility to receive maximal result in the form of profit (or another positive result of activities) for each member of clustering process, as well as substantial reduction of risks.

The most profound definition of cluster has been given by M. Porter, who views "cluster as a group of geographically neighboring interconnected companies and related organizations which work in certain sphere, which are characterized by common activities and supplement each other. Territorial coverage of cluster may vary from production groups of one city or state (region) to country or several neighboring countries.

Clusters have various forms depending on their depth and complexity, but most of them include: companies of "final product" or service; suppliers of specialized factors of production, components, mechanisms, and services; financial institutes and companies in accompanying spheres and governmental structures which influence cluster may be viewed as its part (Popkova \& Tinyakova, 2013b).

Considering global experience of cluster development, it is possible to determining three main "centers": North American, West European, and Asian. At that, the state not only supports the formation of clusters but becomes a part of networks. For example, in Great Britain, the government defined the regions around Edinburgh, Oxford, and South Eastern England as main regions of location for biotechnological forms within cluster. In Norway, government stimulates cooperation between companies in cluster of "marine sector". In Finland, wood industry cluster is very developed - it includes timber and timber products manufacture, production of paper, furniture, polygraphic and relating equipment. Close cooperation of this cluster's companies in distribution of knowledge gives them competitive advantages before main trading rivals. According to experts, Finland is the leader as to the level of research and trechnological cooperation (Popkova et al., 2013).

Thus, the basis for the idea of unification of capabilities and possibilities of subjects of small business with other economic subjects is the use of their possibilities with maximal economic freedom of each member of this informal society and creation of optimal conditions for development. The latter component is the connecting link of cluster.

Subject of small business that forms its strategy of development on the basis of cluster association should determine the sphere of interconnections with other cluster members, which would be a favorable environment for cluster functioning (Xavier et al., 2015).

The next step in implementation of possibilities and formation of the strategy of small business subject if development of the plan of implementation of its potential within strategic directions of development both of the subject and cluster on the whole. The third stage supposes correction of strategic plans of development according to possible influence of factors of external environment on the course of events in the implementation of development strategy. Implementation of these stages has iterative nature, as it is repeated with any change of internal or external conditions and with achievement of intermediary goals.

Classification of clusters is conducted based on certain external limitations of cooperation of its members and directions of their activity. Thus, the following types of clusters are determined: sectorial, geographical (regional), reproduction, consumers', suppliers', informational, etc. At that, a member of one of these clusters can at the same time be a member of another association.

Considering cluster as a variety of economic subjects which are interested in final results of business with optimal condition of development and formation, it is necessary to pay attention to the sense of synergetic effect which emerges during activities of cluster subjects.

On the whole, synergetic effect is characterized by the growth of effectiveness of activity as a result of integration and fusion of separate parts into one system by means of creation of systemic effects of cooperation and full use of own possibilities. As a result, the system receives the excess of total result of activities over the sum of factors which comprise it.

Action of synergetic effect is aimed at qualitative change of the whole system and of the structure and mechanisms of its elements' interaction. Due to these changes, there's constant growth of quantitative indicators functioning, as well as qualitative changes of activities of economic subjects by means of mew possibilities. However, is priority is given to short-term goals with corresponding indicators of growth and profitability, there is a risk of enterprise not achieving its 
long-term strategic goals.

Absence of purpose in the activities of enterprise within diversification also does not stipulate the acquisition or formation of additional advantages by means of synergetic effect. On this basis, subject of small business - as its managing bodies -should rank goals based on certain criteria of priority and find compromises between goals which can possess opposite direction. Receipt of one or several types of synergetic effect will allow each of the subjects of association to reach higher and more stable results of activity.

\section{Conclusion}

Thus, as a result of conducted research, the offered hypothesis was substantiated, and it was found that implementation of cluster initiatives is an effective tool of development of entrepreneurial activities in the agricultural machinery market. Systemic approach, which takes into account main and additional processes, allows determining main directions of development of entrepreneurship of positive character (in view of reflecting and creating necessary elements of synergy at the level of all components of the system and quality of connections) and possible negative ones in view of imbalance of processes of growth of all possible risks, but cannot concentrate attention on the necessary transformation and the level of future problems. Therefore, it is important to conduct detailed forecast of agricultural machinery market and mark the necessary transformations.

Formation of possibilities of entrepreneurial subject is performed by means of effective cooperation on the basis of clustering. The determined possibilities should be implemented during development and realization of strategy of business subject. Substantiation of strategy rises significantly if it is developed stage-by-stage, in certain sequence. Each stage includes procedures which provide the fulfillment of strategy by means of effective use of interconnection and cooperation in cluster.

Usage of possibilities of each cluster subject will allow receiving synergetic effect. A main condition for cluster formation is creation of favorable climate for development of this informal union and for each cluster member. Implementation of cluster initiatives allows using the possibilities and resources of economic subjects more efficiently. Unification of enterprises into cluster allows them not only to function in a more stable way but to additionally control the competitive environment by each cluster member, which reduces the probability of ineffective or irrational managerial decisions and facilitates the development of entrepreneurship.

\section{References}

Carneiro, J., Matos, N., Husted, B. (2015). Free markets and social inclusion: Toward a common goal. Journal of Business Research, 68 (2), 173-176.

Geldes, C., Felzensztein, C., Turkina, E.,Durand, A. (2015). How does proximity affect interfirm marketing cooperation? A study of an agribusiness cluster. Journal of Business Research, 68 (2), 263-272.

Mihajlović, I. (2014). Possibilities for development of business cluster network between SMEs from Visegrad countries and Serbia. Serbian Journal of Management, 9 (2), pp. 145-148.

Popkova, E.G. \& Tinyakova V.I. (2013a). New Quality of Economic Growth at the Present Stage of Development of the World Economy. World Applied Sciences Journal, 5, 617-622.

Popkova, E.G. \& Tinyakova, V.I. (2013b). Drivers and Contradictions of Formation of New Quality of Economic Growth. Middle-East Journal of Scientific Research, 11, 1635-1640.

Popkova, E.G., S.S. Morkovina, E.V. Patsyuk, E.A. Panyavina \& Popov, E.V. (2013). Marketing Strategy of Overcoming of Lag in Development of Economic Systems. World Applied Sciences Journal, 5, 591-595.

Reveiu, A., Dârdală, M. (2015). Influence of cluster type business agglomerations for development of entrepreneurial activities study about Romania. Amfiteatru Economic, 17 (38), 107-119.

Xavier Molina-Morales, F., Belso-Martínez, J.A., Más-Verdú, F., Martínez-Cháfer, L. (2015). Formation and dissolution of inter-firm linkages in lengthy and stable networks in clusters. Journal of Business Research, 68 (7), 1557-1562 